\title{
Interdiffusion in Binary Systems during Rapid Heating: Thermoelastic Stress Influence
}

\section{M.V. Yarmolenko}

Cherkasy Engineering and Technological Institute, Cherkasy, Ukraine

Keywords: Interdiffusion, Thermoelastic Stress, Rapid Heating

If vacancies of a binary metallic system A-B have the potential energy $\mathrm{W}_{\mathrm{v}}$ depending on position, one can find the force, acting on a vacancy in such field

$$
\mathrm{F}_{\mathrm{v}}=-\operatorname{gradW}_{\mathrm{v}}
$$

If the system is under stress $\sigma$, and if a vacancy in the solid is modelled as the centre of negative dilatation, the potential energy of a vacancy is given by

$$
\mathrm{W}_{\mathrm{v}}=-(\Delta \omega \operatorname{tr} \sigma) / 3 \quad \Delta \omega=\omega_{\mathrm{v}}-\omega_{\text {atom }}
$$

Consequently, one can determine vacancy flux due to potential energy gradient:

$$
\begin{aligned}
& \mathrm{j}_{\mathrm{v}}^{\sigma}=\mathrm{C}_{\mathrm{V}} \mathrm{D}_{\mathrm{V}} \mathrm{F}_{\mathrm{v}}(\mathrm{kT})+\left(\mathrm{D}_{\mathrm{B}}-\mathrm{D}_{\mathrm{A}}\right) \operatorname{grad} \delta \mathrm{C}_{\mathrm{B}}{ }^{\sigma} \\
& \mathrm{C}_{\mathrm{V}} \mathrm{D}_{\mathrm{V}}=\mathrm{C}_{\mathrm{A}} \mathrm{D}_{\mathrm{A}} *+\mathrm{C}_{\mathrm{B}} \mathrm{D}_{\mathrm{B}} *, \quad \mathrm{C}_{\mathrm{A}}+\mathrm{C}_{\mathrm{B}}=1
\end{aligned}
$$

This vacancy flux leads to appearance of atomic fluxes of atoms A and B in opposite direction (in the lattice reference system):

$$
\mathrm{j}_{\mathrm{i}}=-\mathrm{C}_{\mathrm{i}} \mathrm{D}_{\mathrm{i}} \mathrm{J}_{\mathrm{v}}^{\sigma} /\left(\mathrm{C}_{\mathrm{V}} \mathrm{D}_{\mathrm{V}}\right)-\mathrm{D}_{\mathrm{A}} \mathrm{D}_{\mathrm{B}} /\left(\mathrm{C}_{\mathrm{A}} \mathrm{D}_{\mathrm{A}}+\mathrm{C}_{\mathrm{B}} \mathrm{D}_{\mathrm{B}}\right) \operatorname{grad} \delta \mathrm{C}_{\mathrm{i}}^{\sigma}
$$

$$
\mathrm{i}=\mathrm{A}, \mathrm{B}
$$

Besides, there are diffusion fluxes of atoms $\mathrm{A}$ and $\mathrm{B}$ (in the lattice reference system)

$$
\mathrm{j}_{\mathrm{i}}=-\mathrm{D}_{\mathrm{i}} \operatorname{grad} \mathrm{C}_{\mathrm{i}} \quad \mathrm{i}=\mathrm{A}, \mathrm{B}
$$

One can find resulting flux relatively to the Matano interface

$$
\begin{gathered}
J_{B}=-J A=-\left(D \operatorname{grad} C_{B}+C_{A} C_{B}\left(D_{B}^{*}-D_{A}^{*}\right) F_{v} /(k T)+D \operatorname{grad} \delta C_{B}{ }^{\sigma}\right) \\
D=C_{A} D_{B}+C_{B} D_{A}
\end{gathered}
$$




\section{Diffusion and Stresses}

For describing of a phase growth with the range of homogeneity $\Delta \mathrm{C}$ one can apply the constant flux approximation $[1,2]$

$$
\begin{aligned}
& \mathrm{J}_{\mathrm{B}} \approx \text { const }=-\left(\mathrm{D} \Delta \mathrm{C} / \Delta \mathrm{X}-\mathrm{D}^{*} /(\mathrm{kT})\left(\Delta \mathrm{W}_{\mathrm{v}} / \Delta \mathrm{X}\right)+\mathrm{D} \Delta \delta \mathrm{C}^{\sigma} / \Delta \mathrm{X}\right), \quad \mathrm{C}=\mathrm{C}_{\mathrm{B}} \\
& \mathrm{D}=(1 / \Delta \mathrm{C}) \int_{c}^{c+\Delta c} \mathrm{D}(\mathrm{C}) \mathrm{dC} ; \mathrm{D}^{*}=(1 / \Delta \mathrm{C}) \int_{c}{ }^{c+\Delta c} \mathrm{C}_{\mathrm{A}} \mathrm{C}_{\mathrm{B}}\left(\mathrm{D}_{\mathrm{B}}{ }^{*}-\mathrm{D}_{\mathrm{A}}{ }^{*}\right) \mathrm{dC}
\end{aligned}
$$

Taking into account that concentrations at the interfaces practically are not changed under stress, one can neglect the last term:

$$
\mathrm{J}_{\mathrm{B}}=-\mathrm{D} \Delta \mathrm{C} / \Delta \mathrm{X}+\mathrm{D} * /(\mathrm{kT})\left(\Delta \mathrm{W}_{\mathrm{v}} / \Delta \mathrm{X}\right) \approx \mathrm{const}
$$

We have two situations (if, for example, $\mathrm{D}_{\mathrm{B}}{ }^{*}>\mathrm{D}_{\mathrm{A}}{ }^{*}$ ):

1. $\Delta \mathrm{W}_{\mathrm{V}}>0$. The phase grows more slowly, if

$$
\Delta \mathrm{W}_{\mathrm{v}}<\mathrm{D} \Delta \mathrm{C} \mathrm{kT/ \textrm {D } ^ { * }}
$$

And if $\Delta \mathrm{W}_{\mathrm{V}} / \Delta \mathrm{X}=$ const $=\mathrm{K}$, one can find maximum width of phase

$$
\Delta \mathrm{X}_{\max }=\mathrm{D} \Delta \mathrm{C} \mathrm{kT} /(\mathrm{D} * \mathrm{~K}),
$$

so stress gradient can stop the phase growth.

2. $\Delta \mathrm{W}_{\mathrm{V}}<0$. The phase grows more rapidly.

If $\Delta \mathrm{W}_{\mathrm{V}}$ is small, the concentration profile tends to form a step ( $\lceil$-like shape ).

If $\Delta \mathrm{W}_{\mathrm{V}}$ has a great value, it is possible for atoms to diffuse up to the concentration gradient, if mutual solubility of substances A and B is limited.

The analogical concentration profile is determined after interdiffusion during rapid heating of FeTi samples ( -like shape) [3].

The force, acting on a vacancy, is directed from Ti to Fe and $\mathrm{D}_{\mathrm{Fe}} *>\mathrm{D}_{\mathrm{Ti}}{ }^{*}$.

The stress gradient arises during rapid heating due to difference between thermal expansion coefficient of Fe and $\operatorname{Ti}\left(\alpha_{\mathrm{Fe}} \approx 2 \alpha_{\mathrm{Ti}}\right)$.

1. A. M. Gusak, M. V. Yarmolenko A simple way of describing the diffusion phase growth in cylindrical and spherical samples // Journal of Applied Physics. - 1993. - Vol.73, №10. - p. 4881-4884. 2. M. V. Yarmolenko Deviation from Parabolic Growth of Phase Layers in Cylindrical and Spherical Samples: Curvature and Internal Stress Influence // Proceedings of PTM'94 Conference Solid - Solid Phase Transformations: Minerals, Metals and Materials Society (USA). - 1995. - pp. 1177 - 1182.

3. Yarmolenko M. V. Kinetyka utvorennya dyfuziynoyi zony pid chas shvydkogo nagrivu binarnych zrazkiv // Visnyk Cherkaskogo inzhenerno-tekhnologichnogo instytutu. - 1996. - N1. - P. 34 - 40. 